\title{
Suburbia as a battlefield between society, environment and planning strategies
}

\author{
R. Barelkowski \\ West-Pomeranian University of Technology, Szczecin (ZUT), Poland
}

\begin{abstract}
The observation that certain spatial phenomena appear as a result of overall socio-economic mechanisms is not new. Thus it is not surprising that the problem of urban sprawl reached Central and Eastern Europe some years ago, being a vivid reminder of both the transformation of the socio-political system and the lack of control regarding the quality of urban space. In the majority of cases these European countries were unable to accommodate the dynamic emergence of market forces consuming once rural areas around urban agglomerations, giving ground to chaotic arrangements and exploiting the most precious and pristine natural resources.

This paper discusses the implementation of a county scale planning procedure with specific, targeted mechanisms adjusted to the Polish legal system in order to illuminate the state of spatial planning and the difficulty in establishing rules of sustainability twenty years after the transformation. Using the case of Rokietnica, a neighboring agglomeration of Poznan, it describes culturally and environmentally oriented mechanisms focused on the conciliation of societal needs, the unstoppable but controllable development opportunities, fragile, yet more and more valuable attributes of cultural landscape and charming natural settings.
\end{abstract}

Keywords: quality of the environment, social and economic aspects in heritage, social participation, planning strategies.

\section{Suburban tensions - environmental problems}

Urban sprawl has become one of the major problems in the second half of the $20^{\text {th }}$ century as a result of uncontrolled urbanization fuelled by civilization processes and thus not restricted to the interest of architects and planners only. 
This sprawl has been observed in agglomerations with the most dynamic trends to concentrate social activities, to provide employment, and to generate proper service network and cultural facilities. Though the cities of the New World (North and South America) and the Western Europe were good examples of what awaits transforming countries [1], these lessons were probably never properly learned. The patterns of change of the urban landscape seem to repeat history in an accelerated manner, suited to the rate of implemented changes in Central European countries.

There are several tendencies in urban sprawl that are particularly troublesome for the quality of the environment [2]. In order to eliminate or to attenuate negative phenomena it is indispensable to diagnose them with a reference to other known examples. The first issue is related to the consummation of the land and its extensive use for investment purposes. The source of this process is mostly socio-economical, rarely referring to environmental (e.g. physiographical) conditions. The results cannot be explained as being rational, while the transformation of the environment cannot be reversed, the land is used extensively and most often in the cheapest way possible, the basic force behind it being the market value of the real estate, which is fluctuating, temporary and unstable and thus inadequate to determine the guidelines for environmental maintenance. The second phenomenon is related to the inability of implementing a natural state of equilibrium, when giving ground to spontaneous development. Even if urban fabric may be taken (conventionally) as a fully fledged alternative to natural habitat, it is not possible to avoid mechanisms of control and management when expecting a balanced urban environment, with a proportional composition of various supplementing functions. To illustrate this problem one may take the example of cultural facilities or greening areas, so unrewarding and opposite to the typical notion of the marketforces. In sprawl there is no place or too little place for this kind of facilities, while development is not justified by purely market driven arguments. Thus the transformation of the environment results in acquiring a disturbed system in which rarely quality of space can be maintained, architectural or urban values may successfully replace natural features and the quality of life is below expectations, only seemingly unexpected. The third phenomenon is the increased discomfort of human life, related to the unbalanced relations between living place and working place, living place and recreation place, accommodation of contradictory social expectations of stability and change. Traffic jams, industrial smoke and noise; all these attributes of large agglomerations indicate the commonness of the sprawl and its presence in the majority of cities throughout the world. The fourth tendency is related to the processes of nature. Nature is devastated in the vicinity of the agglomeration and it is often strongly and negatively affected in other areas. The centripetal development of urban areas leaves retreats of wildlife isolated, enclosed in urbanized or semi-urbanized areas, with its connections broken. This results in the decreasing number of especially larger species, synanthropization and changes in microclimatic conditions. The fifth tendency mentioned in this article (while it does not deplete the list of negative processes) is the socio-cultural diminishing and weakening of local communities. Communities rely on an 
efficient connection with their environment, both transformed and natural. Their condition is a reflection of the ability to generate a cultural identity using the specificity of the area, its "ingredients", in order to produce and maintain culture in a creative way. It makes cultural identity and spatial identity so much connected - spatial identity cannot be understood as a separate entity, it is rather an entity dependent on how a social culture interacts with its own history (in all its complexity) and with a natural setting, it usually thrives. Urban sprawl homogenizes the environment and erases the diversity leaving but the differences in geology - land masses too expensive to be moved.

\section{An uneasy coexistence}

Although urban sprawl has been described, diagnosed, and criticized and its socio-economic mechanisms are recognized, it seems that Central and Eastern Europe will be able to attempt more organized approach to this issue and perhaps be more successful. But the transformation of the socio-political system with all its economic consequences appeared to supersede the question of quality of space. The control regarding the quality of urban space has been neglected and its importance understated. In the majority of cases these European countries were unable to accommodate the dynamic emergence of market forces, hopelessly consuming once rural areas around urban agglomerations, allowing for chaotic arrangements, parasitizing the most precious and pristine natural resources in an attempt to exploit them. There were almost no lessons learned by the examples from the United States, Western Europe, or the more disastrous examples from South America and Asia.

Today, twenty years after the turning point, Central and Eastern Europe experience the consequences of this kind of spatial "freedom". This is also the case of Poland, and the relationship between one of the larger Polish agglomerations - Poznan - and its small, neighboring county - Rokietnica, can be used as an example. Poznan has almost 600.000 inhabitants and is an important industrial and cultural center of the western part of Poland. Rokietnica shares its administrative border with Poznan along the biologically active area of Kierskie lake, with its greening areas, marshes, organic soil resources, along two small streams, one feeding the lake, one discharging water from it. This relatively small county (the smallest administrative area) has no more than 15.000 inhabitants, spread over an area that is one third of the surface covered by urbanized structure of Poznan. The county of Rokietnica maintained its rural character as well as its natural resources, which - despite the low factor of woodlands - contain protected landscape, a few forest complexes, a land configuration typical for the landscape of Great Poland in other areas, many interesting natural forms and traces of history, including monuments, architectural objects and archeological sites. The pressure to develop housing, residential areas around Poznan, has left Rokietnica, at least for the time being, almost intact. Its proximity to the northern border of a large city and its assets related to natural settings apparently didn't match developers' preferences related to good transportation and communication conditions, thus this type of 
interventions in space was focused on three sites: on the edge of the green corridor along the Samica Pamiatkowska river, in the central village (Rokietnica), and in the specific settlement divided by the borderline between Poznan and Rokietnica (Kiekrz), with its most significant part outside of the county. But recently the interest in locations in Rokietnica has been growing stronger, and the process of exploitation of natural resources has begun in many places, profiting from unclear spatial regulations and legislative acts.

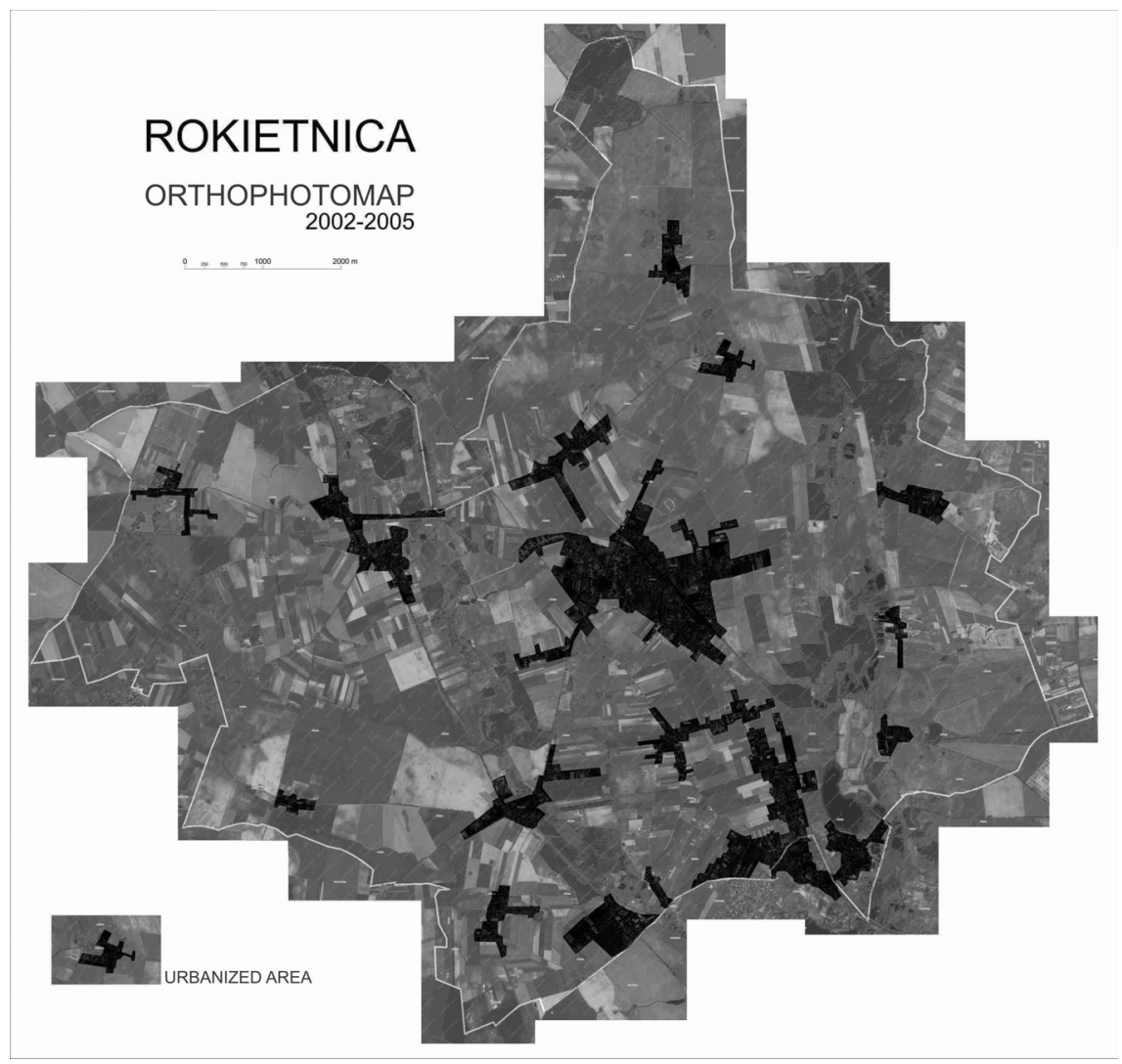

Figure 1: Rokietnica county, indicated urbanized areas and borderline, orthophotomap.

All above mentioned five results of urban sprawl are evident in the case of Rokietnica. There is an extensive land use with chaotic developments, partially dispersed in the proximity of greening areas, partially filling both sides of the main routes connecting villages, increasing the level of dangers (traffic issues), problems of rational management of geodesic divisions and complicating ownership relations. For now, the majority of developments strengthen the unwanted profile of a tendency called "agglomeration bedroom" in Poland, homogenizing functions by restricting them to residential areas only. Services 
are rare and random, while the urban space has never been properly stimulated and densified. There are but few working places non-related to the diminishing agricultural production and the already mentioned services are underdeveloped, thus only a small percentage of inhabitants find work in the county itself. The communication and transportation network is inadequate, resulting in increasing time needed to reach the center of Poznan or any other neighboring county directly connected to Poznan. A distance of $10 \mathrm{~km}$ takes $45 \mathrm{~min}$ instead of the usual 25-30 min which is the average for similar areas. Nature is losing more and more its struggle to survive while many people use legal tricks to set up their homes in pristine locations - due to the lack of authorized master plans and a legal system focused on legal aspects but disregarding the principles of sustainable development. Finally there is a significant problem of the absence of social identity related to the location, to its physiographic characteristics and cultural profile.

\section{The field of struggle}

Can these tendencies be countered efficiently? The answer is not a simple one, because short-sighted economical benefits and political gains often appear to be more tempting due to direct, measurable and quickly consumable material effects, resulting in marginalizing problems of environmental equilibrium seen in a wide perspective, in a time span of decades. What's more, diagnosis is much easier, than prognosis - it is easy to distinguish negative tendencies and announce similar patterns in various places throughout the world, harder to find a remedy that could be applied universally. In fact, it is this generalization of problems that reflects the deterioration of the locality and the countermeasures should rather reflect the nature of the required status of the environment, being as individual as diverse habitats are.

Naturally, the problem cannot be solved merely by intervention through planning procedures and imposing its rules on land development. To receive positive results political support, social understanding and conciliation skills appear very important in the acquisition of the principal goals in the field of architecture, cultural landscape or spatial planning. It is especially indispensable when the damage is already done, while it proves that both authorities and local society are unable to comprehend and execute properly the duty of securing proper balanced development conditions. Therefore core design or core planning efforts have to be accompanied by simultaneous education and negotiation activities.

How can it work, when the system (e.g. legal system) has so many deficiencies or flaws? This is the battlefield - the area, where planning theory and planning guidelines are confronted not only with specific individual requirements, but with a particular social and political reality. General ideas or we may use this word - ideals have to be adjusted and re-formulated individually, too. General definitions have to be reworked and conditionally adapted to reality with the conscious notion that neither reality is perfect, nor ideals can be implemented in a perfect way. To be less obvious - the conscience 
of what has to remain in the core definition of the basic ideal of spatial planning (e.g. sustainability) and what has to be redefined is the first step to understand what this particular concept means to selected cultural landscape and how it may be implemented.

This field of struggle is well known to planners - the conflict between short term and long term perspectives, between direct political gains and safe political idleness, between social populism in investment strategies and social risk in some fundamentally important concepts.

\section{The tools}

Planning ideas rarely have the comfort to be discussed and afterwards successfully applied. The time required for the implementation of proper mechanisms, namely transmitting planning rules to physical arrangements, as well as the degree of unpredictability, leave planning efforts without ultimate guarantees. Nevertheless, it is worth to correlate general principles and individually prepared guidelines.

In the county of Rokietnica previously elaborated selected components of CSSM (Complex System of Spatial Management) have been used to reshape the former spatial policy of local authorities. CSSM was proposed as a system to organize spatial planning in a bottom-up structure, initiating processes on lower levels of administration. The expected difficulties with the administration on higher levels (especially the regional level - powiat and voivodship) were already accommodated - the system allowed for a partial, modular implementation, and did not require all components when providing mechanisms facilitating the improvement of the quality of spatial regulations. The internal organization of CSSM has been described by Barelkowski [3], so here it is only necessary to give a brief explanation. There are two structural frames of the system - one vertical, hierarchical are called levels of the system, the other one horizontal, and parallel in their application and operation activities, called constituent methods. Successful implementations are for now restricted to local level only and for planning reasons the group of methods can be limited to three - ECA, P.R.S., and SSP, with the first as a reference basis preceding the application of the latter two. ECA is an acronym for Environmental and Cultural Analyses, comprising multiple investigations and providing a unified library of data with internal cross-references with the aim to reveal various and complex spatial relationships and, what is more important, providing a reasoning and validation basis allowing to construct a proper critical framework and objectifying the evaluation process. This is a strategic moment - it is decided then, whether planners will be able to monitor tendencies, understand them and attempt to correct their evolution (in order to improve the environment) or they will blindly respond to symptoms versus requests, limiting their activities to an intervention type of planning [4]. P.R.S. method of master planning (Planning References - Social activities) strongly accentuates the connection between spatial issues and multifaceted aspects of human-nature relationship. SSP (Systemic Social Participation) brings participation in the process and vitalizes 
the planning efforts through constant confrontation with changing needs, evaluation and comments among others. These three (and some other) components were designed to provide tools, independent of regional level management (or its absence). P.R.S. has been implemented successfully in 2000 , SSP in 2001 and ECA in 2005, all feeding planners with indispensable information, broadening the scope of interest and, at the same time, an understanding of the environment touched by planning activities.

However, these are not successes that are worth being discussed here but failures. Despite the basic concept of CSSM, intended to work as efficiently as possible in particular conditions - not necessarily implemented completely, not necessarily $100 \%$ effective -after six-seven years it appeared that some additional concepts should complement the system. The original idea was evoked by problems with balancing several seemingly contradictory trends in land development and it was urgent to look for adequate mechanisms to be able to match the challenge.

\section{The application}

The battlefield for planners - quoting the title of the article - had to be redefined by going back to the source of the problem, by researching the nature among the users of the space and among the "players" who govern and influence spatial management. As a result, several principles have been reworked and new ones have been formulated to supplement the system.

One of the most severe problems of planning is very general, but its symptoms are so diverse and fragile, relating to multiple factors, that it is an extremely difficult task to deal with it - the anticipation of things to come. This imaginative process must occur when going beyond action planning. But on a local level this issue presents itself in a very practical set of decisions influencing the economic conditions of the individual inhabitants. Thus we may call it the problem of ambivalent focus when simultaneous consideration of interweaving large scale and smallest scale needs, privileges and responsibilities denounces. This is seemingly so obvious - the clash between public and private interest, the ownership rights and, more widely, constitution freedoms versus rights of the community, privileges and preferences of stronger players - investing companies, prominent operators, infrastructural management bodies. Large scale descriptions prove to be much simpler than individual attempts to conciliate this kind of problems in a real situation, in particular local conditions and when economical responsibility isn't an abstract issue to deal with.

Local planning problems serve the creation of conditions supporting local development and/or preservation of natural resources. The practice observed before implementing CSSM in Rokietnica proved that attenuation of the above mentioned possible conflicts lay in repeating the bottom-up way of thinking about the spatial problems of the environment. While a wide perspective is necessary so as not to lose the scope of principles, the detailed need becomes the starting point for reversed analysis and exploration of competitive theses - how the future of a selected place may look like in 10 years, 20 years? The reverse 
analysis is used to determine real, legal and organization means to acquire the expected status of the environment. This status is to be seen in a wide picture, implementing national and regional programs, sensitive for wide scale tendencies, but for the benefit of and with the focus on strict location. As we can see, the discourse will evidently go back to general issues, but not before its individual implementation is considered through real, practical decisions and actions.

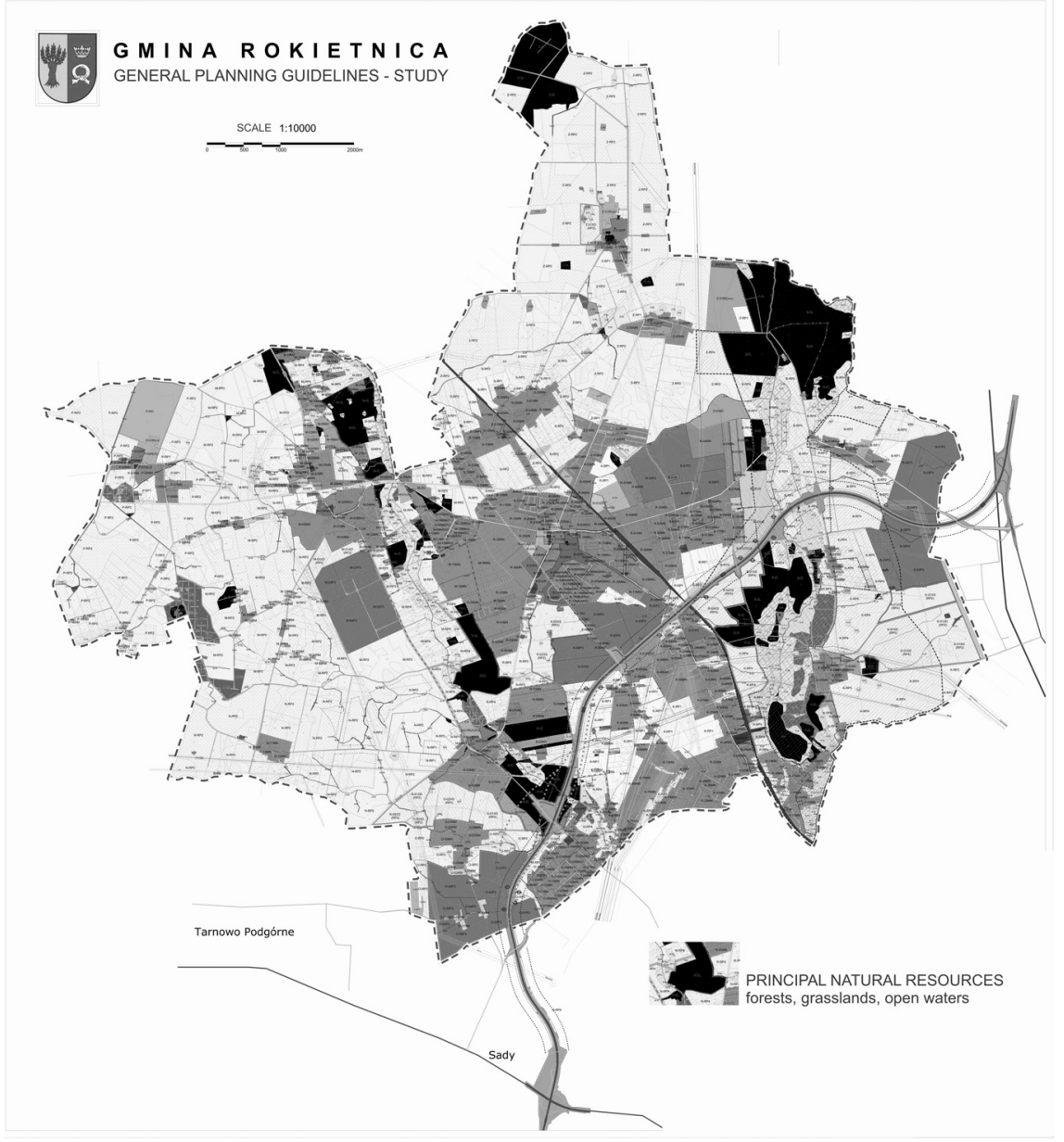

Figure 2: General planning guidelines for Rokietnica county, elab.: armageddon biuro projektowe 2009, darkened principal natural resources.

The second field of struggle is administrative in its nature. It is the procedural aspect of the ability to incept spatial solutions when they are needed. In Poland the master plan requires no less than 9 months to define development and 
management rules to be implemented, but only in the case if this master plan is univocal with general planning guidelines (GPG - studium uwarunkowan i kierunkow zagospodarowania przestrzennego) voted for the area. If changes in GPG are also necessary to allow the master plan to fulfill its intention, the schedule grows to 18 months and more. The principle of the master plan as alocal act of law makes it, in combination with the above, extremely inefficient to plan for changes and applying for changes is a painful and long process, disliked by many of the local authorities, tired with fighting regional authorities to win some advantages and, of course, some financial support, especially for unprofitable programs (like those in preservation of the wildlife).

How to avoid the conflict between real requirements and legal regulations, which are binding - a perfect consonance between GPG and any related master plan is imposed by the act on spatial planning? Not all obstacles may be overcome, but scenario-based (script) planning on county level as well as scenario mechanisms embedded in master plans can serve the purpose. The experience from previous planning elaborations was used to implement development scripts for crucial areas, allowing for a plural, varied land development. This is the moment when ECA and reference component of P.R.S. method mutually shape the anticipative potential of the planning team and the quality of the environment on the lowest level, with a direct impact on the use of space. Scenario-based planning is much more complicated, when it comes to the master plan, an excerpt, selected area of a usually smaller size (typically few to tens of hectares). This method of working requires comprehensive coordination with county level (but still it's enough to do it on local level only). Scenarioregulated zones in Rokietnica were used as crucial areas to accommodate the pressure of the development, but also to balance the types of development by encouraging more economically oriented industrial zones providing working places for the inhabitants. The regional development of a national route - the expressway S-11 - was the pretext to combine a large scale transformation of land induced by road works with connected zones in the impact zone of S-11. It enabled to use a typical solution of overlapping emission areas - reducing the consummation of land and impact on natural resources and landscape. Many issues related to scenario-based planning were described by Barelkowski [5].

The expressway has an enormous impact on the environment. It adds to other spatial limitations, complicating the network of infrastructure and its impact on development areas, especially on the continuity of urbanized fabric. One stripe of land is enclosed between the border of Poznan and the expressway, the other one, the northern one, is larger and not so much affected by the processes of urban sprawl as the southern part. The route splits continuous stripes of greening areas and disturbs the land use profiles as well, both current and planned. Various fractions, lobbying groups and communities struggle to adjust the detailed track of the route for their benefit. This kind of power struggle is (again) typical and places the environmental issues in a weak position. In such a situation the almost only planners' ally is the law, when it properly grounds negotiation skills. But while negotiations and compromise seeking is uncertain, it may be improved by the systemic social participation and facilitation of the 
discourse on the qualities of the environment as well as looking for additional allies among users of space. The SSP is not intended to assure social participation - this is guaranteed by law. The SSP set of procedures are targeted both to acquire vital information (vital also for this power struggle), explain and educate on environmental and planning issues, but also to develop organized elaborations and materials used to establish the optimal planning solutions. Thus it works both ways - as a verification tool used to avoid false preconceptions, and as a manipulation tool used to participate successfully in the power struggle. SSP can be therefore efficient only, when planned in details, oriented on principles and representing clear values and explicit goals.

It is hardly possible to have gains without losses. They were calculated in stipulated the final shape of the GPG elaboration for Rokietnica, as they assumed the release of restrictions south of the expressway, when the allowance for urbanization is natural and the environment is already contaminated with extensive low quality developments. Being more permissive in one place gave the opportunity and arguments to protect other areas not yet touched by the sprawl. It is especially important for Zydowo and Rostworowo with two of the largest forest complexes in the central northern part of the county and along the Samica Pamiatkowska stream, running diagonally south from NNE direction. What's more, planners were able to secure ecological corridors allowing for migrations of species in east-west direction. It was the result of another part of the bargain - local communities, including owners of multiple land plots situated along the designed migration route, were (for now) convinced that this was the only rational condition to maintain biodiversity and attractiveness of the area for recreation purposes. Here, the ECA data proved indispensable (cf. [6]). New to the Polish practice of planning is the complete exclusion of agricultural land from unwanted and unplanned development - contrary to other examples in which especially farms are not subject to planning restrictions.

Again ECA data in combination with SSP, a carefully arranged schedule and "screenplay", were key elements when attempting to implement the protection of the historical heritage and cultural landscape. Currently absent in Polish legal system, settlement typologies and non-registered interesting architectural objects are subject to legal protection. Therefore the protection could rely on general directives included in an act on preservation and conservation of monuments, which is however the subject of public comment and possible protests.

The intention to secure the central areas of selected villages as well as nonregistered objects led to establishing legal definitions for the purpose of master planning as well as the indication of preservation zones. The main spatial patterns of Zydowo, Rostworowo, Sobota, Przybroda, Mrowino were diagnosed and its protection was established, relying on an agreement with interested parties. The concept of preservation of the cultural landscape here - the rural landscape typical for Great Poland, has to juxtapose two standards: traditional and characteristic features of the rural landscape with a contemporary and speculated future standard set of requirements for residential areas and service nodes. This combination is the source for generating architectural typologies, 
while urban/rural typologies are generated as a resultant of the historical shape of the settlement and migration dynamism.

\section{Learning by doing and by example}

The battlefield for planners - quoting the title of the article - had to be redefined by going back to the source of the problem, by researching the nature among users of space and among "players" who govern and influence spatial management. As a result, several principles have been reworked and new ones have been formulated to supplement the system. Both previous experience and current work in the county of Rokietnica were used to establish a concept under the working title "stable values - flexible rules and methods", with a principal guideline to act on three levels: establishing values of the environment with its reference to general values and legal framework by adjusting planning definitions, generating planning rules with obligatory use of typologies, dividing zones of fixed functions and flexible functions using both urban/rural and architectural typologies in case of fixed function, and scenario-based planning in case of flexible functions, finally carefully planning both environmental definitions and procedural steps, while the procedure is also a part of successful plan.

The synergy supported the struggle to protect valuable areas of the county of Rokietnica, deciding that areas proximal to Poznan are lost (to natural environment) and that the compensation should be directed to areas, where natural wildlife can be sustained. This concept protects those resources which are not renewable, but which have some chances as well as a biological potential to remain in balance.

Spatial planning in each particular project in progress is never an easy task. The implementation of any mechanisms or methodology cannot guarantee success, but it can improve the quality of final solutions. What can be done is learning by examples and learning by doing (planning), with the hope that others may profit from your work, whether completely or partially.

\section{References}

[1] Mumford, L., The City in History, Harcourt Inc.: San Diego, 1989.

[2] Bruegmann, R., The Paradoxes of Anti-Sprawl Reform, Urban Planning in a Changing World, ed. R. Freestone, E\&FN SPON: London, pp. 158-174, 2000.

[3] Barelkowski, R., Culturally and contextually sensible strategies of spatial planning. CSSM: Methodology - System - Application, Modernization \& Regionalism. Re-inventing the Urban Identity, eds. C. Wang, Q. Sheng \& C. Sezer, International Forum on Urbanism IFoU 2006, Beijing, TU Delft in co-operation with Tsinghua University Beijing and NTU Taipei Tyler School of Art: Delft, vol. 1, pp. 67-74, 2006.

[4] Barelkowski, R., Wybrane elementy CSSM - kompleksowego systemu zarzadzania przestrzenia w ochronie krajobrazu kulturowego (Selected 
elements of CSSM - complex system of spatial management in the preservation of cultural landscape), Zarzadzanie krajobrazem kulturowym, eds. U. Myga-Piatek \& K. Pawlowska, Prace Komisji Krajobrazu Kulturowego Polskiego Towarzystwa Geograficznego Nr 10: Sosnowiec, pp. 294-301, 2008.

[5] Barelkowski, R., Planistyczne mechanizmy formowania zrownowazonego srodowiska (Planning mechanisms for sustainable environment), EkoArchitektura-Urbanizm-Studia, ed. L. Zimowski, Wydawnictwo Uczelniane WSG: Bydgoszcz, 2009.

[6] Barelkowska, K. and Barelkowski, R., EcoMEM: Evaluating the architectural environment in planning procedures, The Incalculability of Architecture, ed. R. Barelkowski, Osrodek Wydawnictw Naukowych: Poznań, pp. 23-29, 2006. 